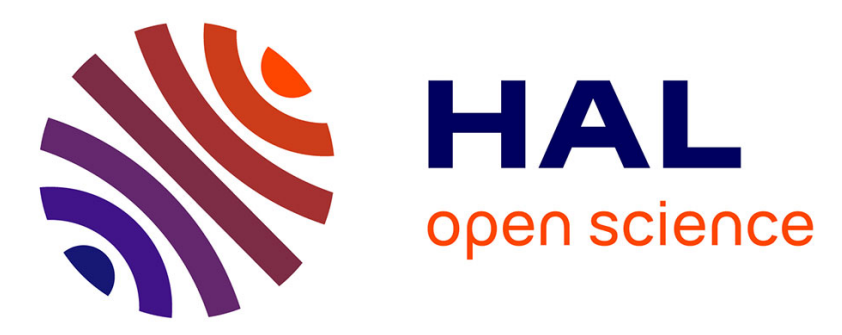

\title{
Modeling the structure of irradiated ocean planets - implications for mass-radius relationships
}

Artyom Aguichine, Olivier Mousis, Magali Deleuil, Emmanuel Marcq

\section{To cite this version:}

Artyom Aguichine, Olivier Mousis, Magali Deleuil, Emmanuel Marcq. Modeling the structure of irradiated ocean planets - implications for mass-radius relationships. European Planetary Science Congress. EPSC 2021, Sep 2021, Virtual Meeting, France. 10.5194/epsc2021-27 . insu-03306171

\section{HAL Id: insu-03306171 \\ https://hal-insu.archives-ouvertes.fr/insu-03306171}

Submitted on 28 Jul 2021

HAL is a multi-disciplinary open access archive for the deposit and dissemination of scientific research documents, whether they are published or not. The documents may come from teaching and research institutions in France or abroad, or from public or private research centers.
L'archive ouverte pluridisciplinaire HAL, est destinée au dépôt et à la diffusion de documents scientifiques de niveau recherche, publiés ou non, émanant des établissements d'enseignement et de recherche français ou étrangers, des laboratoires publics ou privés. 
EPSC Abstracts

Vol. 15, EPSC2021-27, 2021, updated on 28 Jul 2021

https://doi.org/10.5194/epsc2021-27

European Planetary Science Congress 2021

(C) Author(s) 2021. This work is distributed under

the Creative Commons Attribution 4.0 License.

\title{
Modeling the structure of irradiated ocean planets - implications for mass-radius relationships
}

\author{
Artyom Aguichine ${ }^{1}$, Olivier Mousis ${ }^{2}$, Magali Deleuil ${ }^{3}$, and Emmanuel Marcq ${ }^{4}$ \\ ${ }^{1}$ Laboratoire d'Astrophysique de Marseille, Aix-Marseille Université, Marseille, France (artem.aguichine@lam.fr) \\ ${ }^{2}$ Laboratoire d'Astrophysique de Marseille, Aix-Marseille Université, Marseille, France (olivier.mousis@lam.fr) \\ ${ }^{3}$ Laboratoire d'Astrophysique de Marseille, Aix-Marseille Université, Marseille, France (magali.deleuil@lam.fr) \\ ${ }^{4}$ LATMOS, Université Paris-Saclay, Guyancourt, France (emmanuel.marcq@latmos.ipsl.fr)
}

\begin{abstract}
Water-rich planets should be ubiquitous in the universe. Among the current exoplanet populations, many of those worlds are subject to important irradiation from their host star. As a consequence, water-rich worlds display supercritical water layer surrounded by an extended steam atmosphere making them good candidates for matching the observed mass-radius distribution of sub-Neptunes [1]. Here we describe a model that computes a realistic structure for water-rich planets by combining an interior model with an updated equation of state (EoS) for water, and an atmospheric model that takes into account radiative transfer. Our model has been applied to the GJ 9827 system as a test case and indicates Earth- or Venus-like interiors for planets b and c, respectively. Planet $d$ could be an irradiated ocean planet with a water mass fraction of $\square 20 \pm 10 \%$. We also provide mass-radius relationships for water-rich planets and their analytical expression. This allows one to directly retrieve a wide range of planetary compositions, without the requirement to run the model. The possible existence of such planets is discussed in light of atmospheric loss processes, suggesting that some sub-Neptunes are the outcome of planets that lost their $\mathrm{H} / \mathrm{He}$ reservoirs.
\end{abstract}




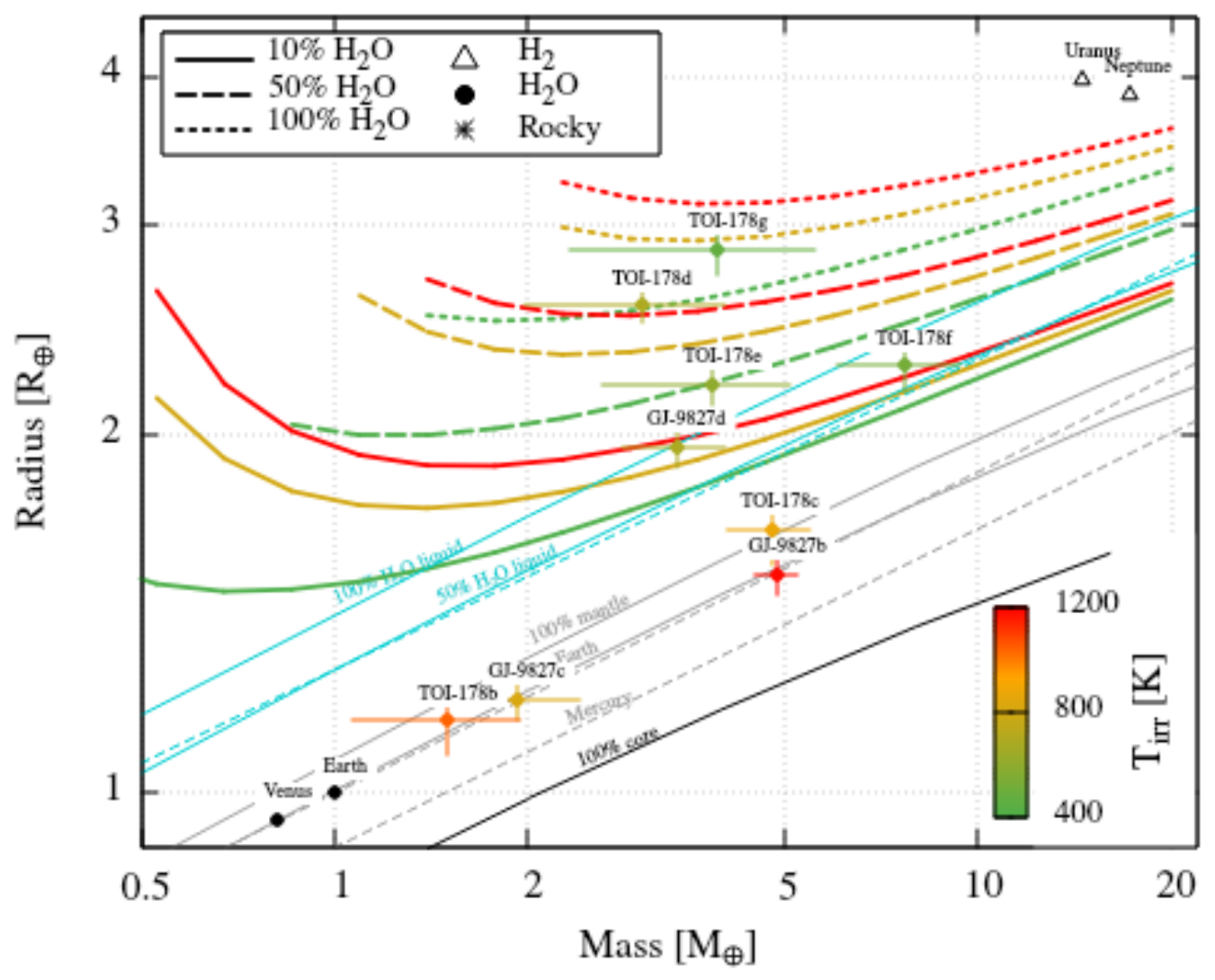

Figure 1. Mass-radius relationships produced by our model (green, yellow and red thick lines) [2], compared to mass-radius relationships of planets with only condensed phases and no atmosphere (black, grey and light blue thin lines) [3,4]. A few planets of the solar system, the GJ-9827 system and the TOI-178 system are shown as well $[5,6]$.

[1] Mousis, O., Deleuil, M., Aguichine, A., et al. 2020, ApJL, 896, L22.

[2] Aguichine, A., Mousis, O., Deleuil, M., et al. 2021, accepted in ApJ.

[3] Zeng, L., Sasselov, D. D., \& Jacobsen, S. B. 2016, ApJ, 819, 127.

[4] Brugger, B., Mousis, O., Deleuil, M., et al. 2017, ApJ, 850, 93.

[5] Kosiarek, M. R., Berardo, D. A., Crossfield, I. J. M., et al. 2021, AJ, 161, 47.

[6] Leleu, A., Alibert, Y., Hara, N. C., et al. 2021, A\&A, 649, A26. 